\title{
What do Medical Students Think about the Clinical Pharmacology Course in the Fourth Year of Medical Education?
}

\section{Berna Terzioğlu Bebitoğlu}

Department of Medical Pharmacology, Istanbul Medeniyet University Faculty of Medicine, Istanbul, Turkey

\begin{abstract}
Introduction: Rational pharmacotherapy training given to undergraduate medical students enables the doctors to treat their patients in accordance with the principles of rational drug use. The present descriptive analysis was carried out on fourth-year medical students to detect their perceptions on this training program using a questionnaire.

Methods: During the academic year of 2018-19, a total of 100 fourth-year medical students attended the one-week clinical pharmacology course. Upon completion, of course, an unnamed questionnaire asking their opinion about the program was given to them

Results: A total of 100 students participated in course, and the percent response to the survey questions was $72 \%$. The postcourse questionnaire results revealed that $77.8 \%$ of the students found the course was useful for medical students, and the students were generally pleased with the components of the program. The highest satisfaction was with the environment being appropriate for expression of their opinions (88.9\%) and discussions conducted in an interactive environment (79.2\%). Most of them answered that they had covered the rationale for personal (P-) drug selection (88.9\%). The lowest satisfaction was with the duration sessions (51.4\%) and duration of education (58.3\%) that the discussion sessions may be shorter in duration while the duration, of course, may be extended to two weeks.

Discussion and Conclusion: In conclusion, the present analysis shows the favorable perception of the students who attended the clinical pharmacology program during the fourth year of medical school. The students stated that education is useful, they actively participated in the discussions, learned P-drug selection, and these will contribute to their professional lives.

Keywords: Education; medical students; personal drug; prescribing skills; rational drug use; rational pharmacotherapy.
\end{abstract}

\footnotetext{
I
}

t is of importance to teach rational pharmacotherapy principles to medical students and to evaluate it regularly also in the post-graduate period. Rational pharmacotherapy training given to undergraduate medical students enables the doctors to treat their patients in accordance with the principles of rational drug use. Rational drug use is one of the most important issues not only for doctors and patients but also for each subject of public, drug industry, health authorities and social security services. Prevention of irrational prescribing is possible through education and it was demonstrated that medical doctors who were trained in rational pharmacotherapy course were able to write rational prescriptions ${ }^{[1-3]}$.

Rational Drug Use was firstly defined by World Health Organization (WHO) in 1985 as a patient using the drug appropriate for his clinical needs, at an adequate dose, for appro-

Correspondence (iletişim): Berna Terzioğlu Bebitoğlu, M.D. Istanbul Medeniyet Universitesi Tip Fakultesi,

Tibbi Farmakoloji Anabilim Dali, Istanbul, Turkey

Phone (Telefon): +90 5324114979 E-mail (E-posta): bernaterzioglu@gmail.com

Submitted Date (Başvuru Tarihi): 01.08.2019 Accepted Date (Kabul Tarihi): 21.08.2019

Copyright 2020 Haydarpaşa Numune Medical Journal

OPEN ACCESS This is an open access article under the CC BY-NC license (http://creativecommons.org/licenses/by-nc/4.0/) 
priate duration, and at minimum cost for both individual and public ${ }^{[4]}$. The use of a drug rationally is possible only when the drug is used according to criteria, such as efficacy, safety, suitability and cost. Thus, irrational drug use occurs when any of these criteria are not considered. According to WHO reports, more than $50 \%$ of the prescribed drugs are used wrongly and/or $50 \%$ of the patients do not use drugs properly ${ }^{[4,5]}$.

It is essential to conduct the rational pharmacotherapy training with active learning methods, such as problembased learning and workplace learning models, in which the learner-oriented education models manage the learners' own learning process, to increase the persistence of learning, and to gain the competence of the physicians to apply the rational drug usage according to the changing conditions in their future clinical practices.

We implemented a rational pharmacotherapy course into the fourth-year clinical pharmacology clerkship at İstanbul Medeniyet University, School of Medicine. The basic pharmacology education is usually instructed by drug-centered lectures in the third year and the topics of clinical pharmacology are discussed in the fourth-year in the clinical pharmacology course program of one week. A standard 6-step WHO model of pharmacotherapeutic approach to the selected indications is taught in this course $\mathrm{e}^{[2,3,6]}$.

On the first day of the 5-day program, the program was introduced in detail also by providing a guiding document regarding the components of the course. The aims and objectives of the program, assessment methods were described, and the expectations of the students were listened. The presentation of "General principles of rational pharmacotherapy" and "MAUA in choosing P-drug" was made. Students were asked to get prepared for the tasks of treatment of two indications, essential hypertension and acute sinusitis. On the other days, the 6-step model of pharmacotherapeutic approach to essential hypertension and acute sinusitis were performed by the participants in small groups and they selected the appropriate personaldrug (P-drug). Case discussions were performed and prescriptions were written for each indication. Meanwhile, lectures named "The principles of prescribing", "prescribing in special populations (such as pregnancy, lactation, pediatric and geriatric)," and "the principles of rational drug use", "pharmacovigilance," "and dose calculation, clinical toxicology" were given at times other than small group discussions.

On the last day, a structured written examination and multiple-choice question examination were applied. The ses- sions were conducted by facilitators who work in the field of pharmacology. The present descriptive analysis was carried out on fourth-year medical students to detect their perceptions on this training program using a questionnaire.

\section{Materials and Methods}

This study carried out in İstanbul Medeniyet University, School of Medicine in Istanbul. During the academic year of 2018-19, a total of 100 fourth-year medical students attended the one-week course named "clinical pharmacology," during which they were taught how to select, decide and apply pharmacotherapy. Upon completion, of course, an unnamed questionnaire asking their opinion about the program was given to them. The questionnaire were analysed retrospectively. The participation depends on voluntary approval. Thus, not all of the students who attended the course filled the form.

\section{Statistical Analysis}

The questionnaire consisted of open and closed-ended questions. The descriptive analysis approach was used in the analysis of qualitative data derived from open-ended questions, and the reactions of the students were evaluated by classifying according to some themes. The results of the questionnaire were expressed as a percentage of the total number of students who filled the forms.

\section{Results}

A total of 100 students participated and the percent response to the survey questions was $72 \%$. The qualitative findings were presented in accordance with the research questions.

The opinions of the students about the constituents of the program, learning methods and exam, duration of education, the facilitators, the students, and interactions and environment and sources of the education were categorized.

The post-course questionnaire results revealed that $77.8 \%$ of the students found the course useful for medical students.

Students were generally pleased with the components of the program (Table 1). The highest satisfaction was with the environment being appropriate for expression of their opinions (88.9\%) and discussions conducted in an interactive environment (79.2\%). Most of them answered that they had covered the rationale for P-drug selection (88.9\%). The lowest satisfaction was with the duration of sessions (51.4\%) and duration of education (58.3\%) as that the discussion sessions may be shorter in duration while the dura- 
Table 1. Students' opinions on the components and method of rational pharmacotherapy course

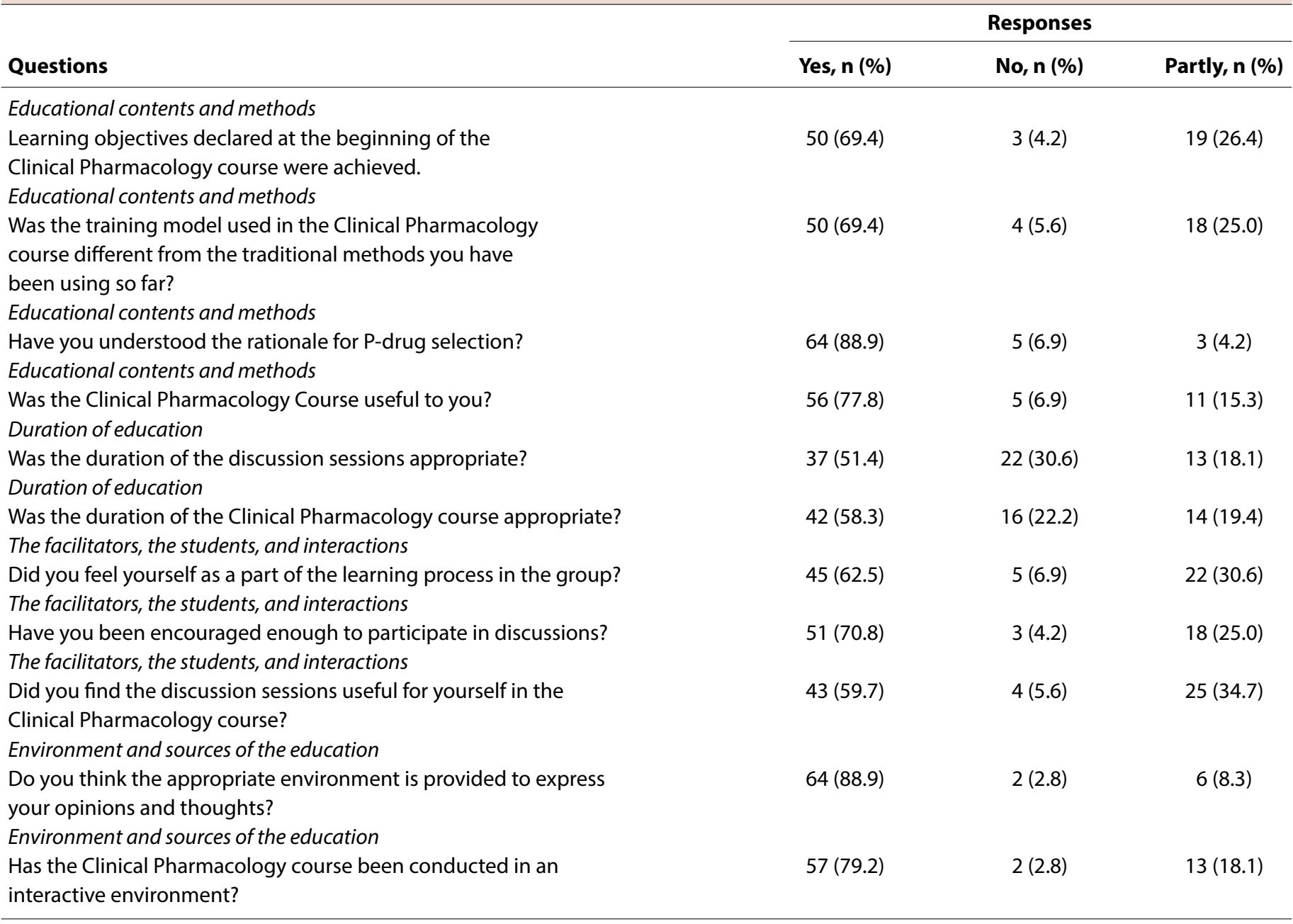

tion, of course, may be extended to two weeks.

Considering the open-ended questions of the students, it was understood that they liked the methods and applications in the program. The model of six-step problem-based method and P-drug selection sessions was appreciated by the students. The students specified that prescribing, case discussions, self-preparation for the sessions were also useful for them, as well as interest and relevance of educators motivated them.

\section{Educational Contents and Methods}

The students $(n=13)$ demanded more different diseases other than hypertension and acute sinusitis. They stated that: "I believe it is a useful experience. I wish I had the chance to discuss not two but several other diseases that are commonly encountered in population.," "There could be acute tonsillopharyngitis or a pneumonia case.", "Once a week should not be, it must be at least three weeks. The treatment of many diseases, such as Diabetes type 1 and type2, acute infections, such as acute gastroenteritis, acute upper or lower respiratory tract infections, hyperthyroidism, or hypothyroidism, can be discussed."

They $(n=23)$ liked the environment for interactive discussions. The most frequent answer to the question, "what did you like about the 'Clinical Pharmacology Clerkship"' was its being interactive. They wrote, "Group discussions were very useful and contributed a lot to our learning". They emphasized that all the lectures, including year three, where basic pharmacology information is taught could be in the same format where interactive discussions are performed. They wrote that "I think that if our lectures in the $3^{\text {rd }}$ class were with an interactive case discussion education model, we would get higher benefit from pharmacology lessons.", "I think it is a very useful course to understand the importance of the p-drug concept and to learn how and where to use the drugs that we have learned theoretically in preclinical years of education."

The education program also included the presentations 
related with clinical pharmacology, such as "The principles of prescribing", "prescribing in special populations (such as pregnancy, lactation, pediatric and geriatric)," and "the principles of rational drug use," "pharmacovigilance," "and dose calculation, clinical toxicology." They $(n=15)$ disliked the theoretical sessions as they stated that they had attended these lectures in their preclinical years.

Some students $(n=4)$ expressed their desire not to have examinations, some $(n=2)$ expressed the system of the examination was fair and stated:"I knew an exam was waiting for me when I did not feel the fear of exam grade while studying. I can say that these were the most useful pharmacology lessons for me to date." Few students $(n=2)$ also mentioned that the duration of the course was a short time to prepare for the exam and wrote: "The information queried in the exam is very broad; the time given to us to digest this information is insufficient."

\section{Duration of Education}

Students $(n=20)$ found that the duration of sessions were long, and duration of the course was short. They wrote that "The number of diseases can be increased and the course period can be two weeks." "Modules can be more understandable by shortening the times." "Definitely, time should be for two weeks and should cover at least five modules," "I think the duration of the course can be extended for more efficient learning," "I think the content of the internship is intense so the internship period can be two weeks.," "Unlike conventional medical education, I am happy to be able to participate more actively in the learning process, I wish it would last longer."

\section{The Facilitators, the Students, and Interactions}

Students ( $n=14)$ were appreciated by the facilitators that they were instructional, motivated, nice, and concerned with all components of the course.

Some of the students $(n=5)$ commented on the differences between the readiness of students within the teamwork. As not all students do the job properly in the team, prepare for theoretical information before getting into the class for discussion, they were unable to discuss the topic.

\section{Environment and Sources of the Education}

Students were generally satisfied with the environment and sources of education. Attending the education program in school building away from hospital was liked by two students.

\section{Discussion}

Rational pharmacotherapy education has been implemented in most of the medical faculties in Turkey ${ }^{[7]}$. Although the Groningen model is implemented, there exists differences in practice regarding the duration of education, its location in curriculum, and whether it is integrated into other clerkships or not ${ }^{[2,3,8]}$.

This training model enables therapeutic reasoning and prescribing ${ }^{[1,6]}$. There is a six-step to the process of rational prescribing for medical students throughout their career. In this model the steps are as follows: Step 1: Define the patient's problem; Step 2: Specify the therapeutic objective; Step 3a: Choose your standard treatment (P-drug); Step 3b: Verify the suitability of your treatment (P-drug); Step 4: Start the treatment (write prescription); Step 5: Give information, instructions and warnings; Step 6: Monitor (and stop) the treatment ${ }^{[2,6]}$.

The efficacy of this model is evaluated and compared with other teaching methods in undergraduate medical students resulting as students performed better than the others in both problem solving therapeutic decision-making, and good prescribing ${ }^{[3,9]}$.

In this study, we evaluated the rational pharmacotherapy education in our faculty, and we analyzed the perception of fourth-year medical students. They were mostly appreciated by the outcomes of the course. They gave positive feedback, especially about the education method and P-drug selection. This finding is also consistent with other reports where the students' opinions are usually favorable ${ }^{[10-13]}$.

The students were appreciated with especially interactive discussions on drug information, case discussions and choosing their personal drug, among many other drugs indicated at that indication. Interactive learning methods, such as problem-based learning conducted in small groups, are demonstrated to have a robust positive effect on learning and skills, including better problem-solving skills and an increase in overall motivation ${ }^{[14]}$. While students are working in groups, they learn from and motivate each other ${ }^{[15]}$. Thus, in clinical pharmacology course, small group activities, preparing a presentation, discussing cases and simulating patient-physician role and prescribing practices were performed. Accordingly, the students liked mostly these activities during education and emphasized to learn all pharmacology topics via this method, which is more effective than lectures. Thus, for context-learning, the lectures in basic and clinical pharmacology can be transformed by incorporating clinical practice and prescription writing skills ${ }^{[9]}$. Recently, it was demonstrated that 
video footages and group discussions added to the course program performed with the WHO model of prescribing method improved the fourth-year medical students' performance in rational pharmacotherapy skills ${ }^{[16]}$.

Prescribing is an essential skill for medical doctors and medical students and young doctors are poor in prescribing ${ }^{[17}$, ${ }^{18]}$. During the course, the students experienced more than once the prescription writing and they indicated that they liked this activity and desire to write more prescriptions. This is consistent with the literature, which states that appropriate education in rational pharmacotherapy prevents irrational prescribing ${ }^{[2]}$. For rational prescribing, it is necessary to write down the name of the drug, its strength, its dosage, its pharmaceutical form with special warnings that should be explained to the patient. Thus, it is essential to know the standard treatment regimen, develop a personal formulary for that treatment. By this training method, while students choose their p-drug among other drug classes, they learn to assess and select a drug based on comparative efficacy, suitability, safety and cost of the drug. They search the drug on market, its strength and its cost.

By discussing non-drug treatment issues, they consolidate the pathophysiology of the disease. While they are verifying the suitability of their p-drug treatment for the patient, they learn to assess each patient as an individual, consider his/her age, concomitant diseases and/or drug uses, and smoking. Thus, they apply basic pharmacology knowledge to a specific patient. This method improves basic pharmacology knowledge, and as reported in other studies, they transfer this knowledge to different patient cases $^{[6,19,20]}$. We have observed the satisfaction of the students during these discussions in groups.

The duration of the course was found to be inadequate by the students, and students reported their requests for the application of $p$-drug selection for more indications. The program seems to be quite successful. However, some modifications may be considered, and more modules can be added even by incorporating the course into the other clinical clerkships. In this way, students will have more opportunities to select P-drug with their colleagues and educators to discuss different case scenarios and to write prescriptions.

The strength of this study is the high response rate, with different opinions providing information. The limitation of this analysis is that it was performed in one site only, and the course's duration and location in the curriculum may differ between medical schools. However, the results of this analysis provide useful information and also may lead to important conclusions for applying corrective measures to improve clinical pharmacology training. Our efforts may be of value in the improvement of clinical pharmacology in undergraduate education consistent with both the national and international competencies ${ }^{[21,22]}$.

In conclusion, the present analysis shows the favorable perception of the students who attended the clinical pharmacology program during the fourth year of medical school. The students stated that education is useful, they actively participated in the discussions, learned p-drug selection, and these will contribute to their professional lives. However, with some modifications in the education program and improvements in education environments, this education will provide more benefits. Our aim is to add more indications and integrate this course with other clinical clerkships. This could require the involvement of more facilitators. Thus, this can be accomplished by training lecturers of other disciplines.

\section{Acknowledgements}

The author thank Elif Oğuz and Nazife Gökçe Acet for their active participation in the teaching/facilitating activities.

Ethics Committee Approval: Retrospective study.

Peer-review: Externally peer-reviewed.

Conflict of Interest: None declared.

Financial Disclosure: The authors declared that this study received no financial support.

\section{References}

1. De Vries TP. Presenting clinical pharmacology and therapeutics: the course in pharmacotherapeutics. Br J Clin Pharmacol 1993;35:587-90. [CrossRef]

2. De Vries TPGM, Henning RH, Hogerzeil HV, Fresle DA. Guide to Good Prescribing - A Practical Manual. Geneva: World Health Organisation, 1994.

3. De Vries TP, Henning RH, Hogerzeil HV, Bapna JS, Bero L, Kafle $\mathrm{KK}$, et al. Impact of a short course in pharmacotherapy for undergraduate medical students: an international randomised controlled study. Lancet 1995;346:1454-7. [CrossRef]

4. World Health Organization. The rational use of drugs : report of the Conference of Experts, Nairobi, 25-29 November 1985. Geneva: World Health Organization, 1985. Available from: https://apps.who.int/iris/handle/10665/37174.

5. World Health Organization Policy Perspectives on Medicines No. 5. Promoting rational use of medicines: core components. Available from: https://apps.who.int/medicinedocs/pdf/ h3011e/h3011e.pdf.

6. Keijsers CJ, Segers WS, de Wildt DJ, Brouwers JR, Keijsers L, Jansen PA. Implementation of the WHO-6-step method in the medical curriculum to improve pharmacology knowledge 
and pharmacotherapy skills. Br J Clin Pharmacol 2015;79:896906. [CrossRef]

7. Akıcı A, Gelal A, Erenmemişoğlu A, Melli M, Babaoğlu M, Oktay Ş. Akılcı ilaç kullanımı eğitimi uygulama sürecinde Türkiye'deki tıp fakültelerinde farmakoloji anabilim dallarının durumunun incelenmesi. Tıp Eğitimi Dünyası 2011;29:11-20.

8. Tisonova J, Hudec R, Szalayova A, Bozekova L, Wawruch M, Lassanova $M$, et al. Experience with problem oriented teaching in pharmacology. Bratisl Lek Listy 2005;106:83-7.

9. Richir MC, Tichelaar J, Geijteman EC, de Vries TP. Teaching clinical pharmacology and therapeutics with an emphasis on the therapeutic reasoning of undergraduate medical students. Eur J Clin Pharmacol 2008;64:217-24. [CrossRef]

10. Karaalp A, Akici A, Kocabaşoğlu YE, Oktay S. What do graduates think about a two-week rational pharmacotherapy course in the fifth year of medical education? Med Teach 2003;25:515-21. [CrossRef]

11. Bilge $S S, A$ kyüz $B$, Ağrı AE, Özlem M. Rational drug therapy education in clinical phase carried out by task-based learning. Indian J Pharmacol 2017;49:102-9.

12. Guney Z, Uluoglu C, Yucel B, Coskun O. The impact of rational pharmacotherapy training reinforced via prescription audit on the prescribing skills of fifth-year medical students. Int J Clin Pharmacol Ther 2009;47:671-8. [CrossRef]

13. Eriksson AL, Wallerstedt SM. Developing confidence in basic prescribing skills during medical school: a longitudinal questionnaire study investigating the effects of a modified clinical pharmacology course. Eur J Clin Pharmacol 2018;74:1343-9.

14. Sivam SP, latridis PG, Vaughn S. Integration of pharmacology into a problem-based learning curriculum for medical students. Med Educ 1995;29:289-96. [CrossRef]

15. Sisk RJ. Team-based learning: systematic research review. J Nurs Educ 2011;50:665-9. [CrossRef]
16. Gelal A, Gumustekin M, Arici MA, Gidener S. Rational pharmacotherapy training for fourth-year medical students. Indian J Pharmacol 2013;45:4-8. [CrossRef]

17. Al Khaja KA, Handu SS, James $H$, Mathur VS, Sequeira RP. Assessing prescription writing skills of pre-clerkship medical students in a problem-based learning curriculum. Int J Clin Pharmacol Ther 2005;43:429-35. [CrossRef]

18. Maxwell S, Walley T; BPS Clinical Section Committee. Teaching safe and effective prescribing in UK medical schools: a core curriculum for tomorrow's doctors. Br J Clin Pharmacol 2003;55:496-503. [CrossRef]

19. Akici A, Gören MZ, Aypak C, Terzioğlu B, Oktay S. Prescription audit adjunct to rational pharmacotherapy education improves prescribing skills of medical students. Eur J Clin Pharmacol 2005;61:643-50. [CrossRef]

20. Vollebregt JA, Metz JC, de Haan M, Richir MC, Hugtenburg JG, de Vries TP. Curriculum development in pharmacotherapy: testing the ability of preclinical medical students to learn therapeutic problem solving in a randomized controlled trial. Br J Clin Pharmacol 2006;61:345-51. [CrossRef]

21. Brinkman DJ, Tichelaar J, Mokkink LB, Christiaens T, Likic R, Maciulaitis R, et al; Education Working Group of the European Association for Clinical Pharmacology and Therapeutics (EACPT) and its affiliated Network of Teachers in Pharmacotherapy (NOTIP). Key Learning Outcomes for Clinical Pharmacology and Therapeutics Education in Europe: A Modified Delphi Study. Clin Pharmacol Ther 2018;104:317-25. [CrossRef]

22. Gülpınar MA, Gürpınar E, Songur A, Vitrinel A. Mezuniyet Öncesi Tıp Eğitimi Ulusal Çekirdek Eğitimi Programı-2014. Available from: https://www.yok.gov.tr/Documents/Kurumsal/egitim_ogretim_dairesi/Ulusal-cekirdek-egitimi-programlari/tip_fakultesi_cep.pdf. Accessed July 01, 2019. 